\section{Variations in treatment of C1 fractures by time, age, and geographic region in the United States: An analysis of $\mathbf{9 8 5}$ patients}

\author{
Sheyan J. Armaghani, ${ }^{1}$ \\ Zachary J. Grabel, ${ }^{2}$ Catphuong Vu,
}

S. Tim Yoon ${ }^{2}$

${ }^{1}$ Florida Orthopedic Institute, Temple Terrace, FL; 'Department of Orthopedic Surgery, Emory University School of Medicine, Atlanta, GA; ${ }^{3}$ Department of Orthopedics and Sports Medicine, University of Washington, Seattle, WA, USA

\begin{abstract}
The purpose of this investigation was to evaluate the variations in the treatment of $\mathrm{C} 1$ fractures over time, by age group, and by geographic region using a nationwide database. The Nationwide Emergency Department Sample (NEDS) database was queried to identify patients $\geq 18$ years who sustained C1 fracture from 2006-2012. Patients were filtered based on the intervention they received: collar, halo, or surgery. Regions of hospital used in analysis were defined as Northeast, Midwest, South, and West. Surgical intervention for C1 fracture increased from $27.1 \%$ of cases in 2006 to $55.4 \%$ of cases in $2012(\mathrm{P}<0.001)$. The rate of collar treatment increased with increasing age. In contrast, rate of halo use decreased with increasing age. A greater proportion of patients in the Northeast were treated by collar compared to all other regions $(\mathrm{P}<0.001)$. We can conclude that there is considerable variation in the treatment of $\mathrm{C} 1$ fractures with regards to age and geographic region. Surgical treatment of these fractures is increasing over time. Future considerations should be given to developing treatment guidelines to decrease variation and potentially create cost-savings.
\end{abstract}

\section{Introduction}

The prevalence of upper cervical spine fractures is increasing over time. ${ }^{1-3}$ Fractures of $\mathrm{C} 1$ are responsible for up to 5$15 \%$ of all cervical spine injuries ${ }^{2,4-7}$ and the diagnosis can be frequently missed. ${ }^{8}$ Although these fractures are becoming increasingly more common, optimal management of $\mathrm{C} 1$ fractures remains controversial.4-6,9-12 Treatment of $\mathrm{C} 1$ fractures may include surgery, halo vest placement, or rigid cervical collar. However, no evidencebased treatment algorithm exists for treating these fractures which has led to wide variations in management. Furthermore, the aforementioned treatment options have only been evaluated in small studies that rarely assess all three potential modalities. ${ }^{6,13}$

Regional variations in treatment strategies have been observed when a clear consensus does not exist. ${ }^{14-16}$ However, regional differences in the treatment of $\mathrm{C} 1$ spine fractures has not yet been evaluated as a potential predictor of treatment.

There is a paucity of data regarding factors that influence the treatment of $\mathrm{C} 1$ fractures. This study analyzed patients with $\mathrm{C} 1$ fractures who were admitted to the hospital through the emergency department (ED) to evaluate the variations in treatment of $\mathrm{C} 1$ fractures over time, by age group, and by geographic location. Since there is no consensus on optimal form of management for these fractures, we expect to find variations in treatment based on time, age, and region. Specifically, we hypothesize that surgical management of $\mathrm{C} 1$ fractures is increasing over time, halo orthosis use has decreased over time, and that there are regional differences in treatment patterns.

\section{Materials and Methods}

\section{Data source}

Data was obtained from the Nationwide Emergency Department Sample (NEDS) compiled as part of the Healthcare Cost and Utilization Project. In brief, the NEDS is the largest all-payer emergency department (ED) database in the U.S., which combines data from the State Inpatient Databases (SID) and State Emergency Department Databases (SEDD) and capture patients who were seen in the ED and admitted to the hospital. Variables included in the database are patient demographics, diagnostic and procedural International Classification of Disease (ICD-9) codes, inpatient charges, length of stay, and hospital region.

The NEDS database was queried to identify patients 18 years and older who were diagnosed with $\mathrm{C} 1$ fracture without neurological injury from 2006-2012 (ICD-9 codes 805.01). Patients with spinal cord involvement and polytrauma injuries, including concomitant cervical spine injuries, were excluded. The rational for this exclusion criteria is that the presence of neurologic deficits and concomitant injuries are generally accepted indications for surgical management. ${ }^{9}$ Subsequently patients were further filtered based on the interven-
Correspondence: Zachary J. Grabel, Department of Orthopedics, Emory University School of Medicine, 57 Executive Park South, Room \#160-5, Atlanta, GA 30329, USA. Tel.: +1.404.7781567 - Fax: +1.404.7788192. E-mail: zgrabel@emory.edu

Key words: C1 fracture, treatment variations, halo, cervical collar.

Contributions: SJA: substantial contribution to conception, design, analysis, interpretation of data, critical revision; ZJG: substantial contribution to drafting the article and critical revisions; $\mathrm{CV}$ : substantial contribution to analysis, interpretation of data; STY: substantial contribution to critical revisions, final approval of the version to be published.

Conflict of interest/funding: SJA, ZJG and CV have no conflicts of interest. STY has received royalties from Stryker Spine and Meditech Spine; research grants from NIH, Biomet, and AO Spine; stock ownership in Phygen, Meditech, and Medyssey.

Received for publication: 18 August 2018. Accepted for publication: 20 October 2018.

This work is licensed under a Creative Commons Attribution NonCommercial 4.0 License (CC BY-NC 4.0).

CC Copyright S.J. Armaghani et al., 2018

Licensee PAGEPress, Italy

Orthopedic Reviews 2018;10:7834

doi:10.4081/or.2018.7834

tion they received: collar (ICD-9 codes 93.52), halo (ICD-9 codes 02.94, 93.41), and cervical fusion (ICD-9 codes 81.01, $81.02,81.03,03.53)$. Patients who had multiple interventions were re-categorized according to the more invasive procedure. Regions of hospital used in analysis were defined as Northeast, Midwest, South, and West.

\section{Statistical analysis}

Univariate analysis was performed for patient characteristics stratified by type of intervention. Linear regression models were used to analyze trends for $\mathrm{C} 1$ incidence rates and treatment type over the six-year study period. Analysis of variance (ANOVA) tests were used to determine differences among procedure groups when stratified by region and age group.

Multivariate logistic regression models were created to determine the independent effect of the covariates of interest on type of intervention received if significant after analysis of variance. This was done by first including all feasible explanatory variables and then using backward elimination to obtain a minimal model. Statistical analysis 
was performed using SAS 9.4 (Cary, NC). All $\mathrm{P}$ values less than 0.05 was considered statistically significant.

\section{Results}

\section{Demographics of cohort and inci- dence of $\mathbf{C} 2$ fracture}

From 2006-2012, 985 patients with the diagnosis of $\mathrm{C} 1$ fracture with documented intervention were identified in the NEDS database. Amongst this cohort, 36.9\% were female, $63.1 \%$ were male and the mean age was 51.2 (Table 1). The incidence of $\mathrm{C} 1$ fractures increased from 2006-2008. From 2008-2009, the incidence of $\mathrm{C} 1$ fractures decreased to a similar rate seen in 2006. The incidence peaked in 2010 (6.2 cases per $100,000)$ and only slightly decreased in 2012 (5.8 cases per 100,000) (Figure 1).

Overall, the majority of patients received halo or surgery for $\mathrm{C} 1$ fractures $(87.9 \%)$. A greater proportion of patients treated by collar were female compared to the halo and surgery groups, respectively (49.6\% vs. $34.4 \%, 35.7 \%, \mathrm{P}=0.0083)$. In addition, the mean age of patients treated by collar was higher than the mean age of those treated with halo or surgery, respectively (62.6 vs. 48.8 or $50.5, \mathrm{P}<0.001$ ) (Table 1 ).

\section{Rate of interventions over time}

Surgical intervention for $\mathrm{C} 1$ fracture increased from $27.1 \%$ of cases in 2006 to $55.4 \%$ of cases in $2012(\mathrm{r}=0.128, \mathrm{P}<0.001)$ (Figure 2). Contrastingly, the rate of halo use decreased from $61.4 \%$ in 2006 to $35.4 \%$ in $2012(\mathrm{r}=-0.125, \mathrm{P}<0.001)$ with the rate in 2006 being significantly higher compared to other years (95\% CI: 49.7-75.9, $\mathrm{P}=0.023$ ). Rigid cervical collar was the least utilized intervention throughout the study period. The rate of collar use did not significantly change during study period $(\mathrm{r}=-0.0051$, $\mathrm{P}=0.819$ ) (Table 2).

\section{Intervention by age group}

The rate of surgery did not significantly change between age groups $(\mathrm{P}=0.410)$. In contrast, the rate of halo use decreased with increasing age (Figure 3). The rate of halo used in patients age $18-49$ was $45.3 \%$ (95\%
CI: $39.7-51.7)$ compared to $23.1 \%$ in patients over the age 85 (95\% CI: $13.9-38.3$, $\mathrm{P}=0.009$ ) (Table 3 ). The odds ratio of receiving a halo is reflected in Table 4 . The rate of collar treatment increased with age. $7.3 \%$ of cases received collars in patients age $18-49$ compared to $41.5 \%$ of cases in patients who were 85 and older $(\mathrm{P}<0.001)$ (Table 3). Furthermore, there was increased

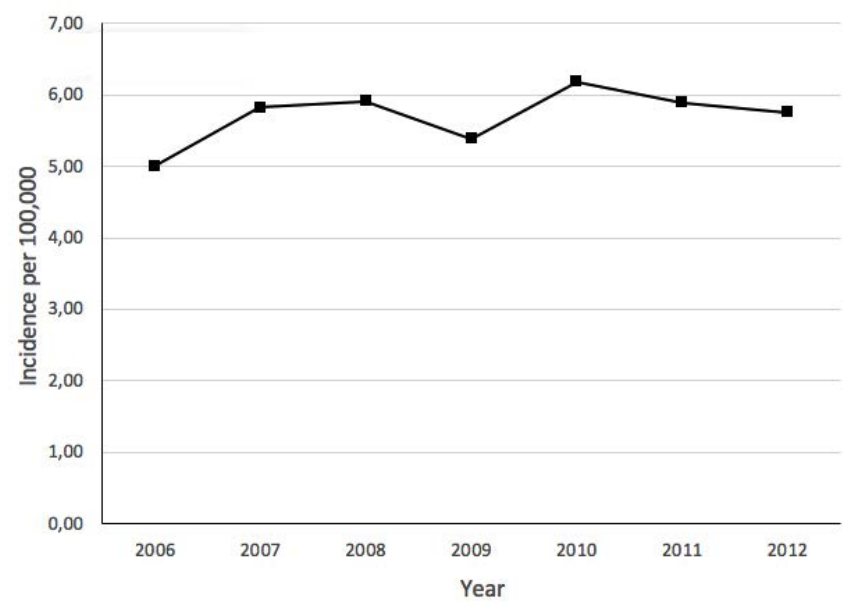

Figure 1. Incidence of C1 fracture per 100,000 hospitalizations from 2006-2012.

Table 1. Characteristics of patients with $\mathrm{C} 1$ fracture who received intervention.

\begin{tabular}{lccccc} 
Characteristic & Total & Collar & Halo & Surgery & P value \\
N (\%) & 985 & $119(12.1)$ & $421(42.7)$ & $445(45.2)$ & - \\
Female & $363(36.9 \%)$ & $59(49.6 \%)$ & $145(34.4 \%)$ & $159(35.7 \%)$ & 0.008 \\
\hline Age (\% SD) & $51.2(20.8)$ & $62.6(22.7)$ & $48.8(19.3)$ & $50.5(20.8)$ & $<0.001$ \\
$18-49$ & $490(49.8)$ & $36(7.4)$ & $222(45.3)$ & $232(47.4)$ & \\
\hline $50-64$ & $214(21.7)$ & $21(9.8)$ & $106(49.5)$ & $87(40.7)$ & \\
$65-74$ & $101(10.3$ & $16(15.8)$ & $41(40.6)$ & $44(43.6)$ & \\
$65-84$ & $115(11.7)$ & $19(16.5)$ & $37(32.2)$ & $59(51.3)$ & \\
$85+$ & $65(6.6)$ & $27(41.5)$ & $15(23.1)$ & $23(35.4)$ & \\
\hline
\end{tabular}

Table 2. Intervention for $\mathrm{C} 1$ fracture from 2006-2012 ( $\mathrm{N}=985)$.

\begin{tabular}{|c|c|c|c|c|c|c|c|c|c|c|c|c|c|c|c|}
\hline & \multicolumn{2}{|c|}{2006} & \multicolumn{2}{|c|}{2007} & \multicolumn{2}{|c|}{2008} & \multicolumn{2}{|c|}{2009} & \multicolumn{2}{|c|}{2010} & \multicolumn{2}{|c|}{2011} & \multicolumn{2}{|c|}{2012} & \multirow[t]{2}{*}{ P value } \\
\hline & n & $\%$ & n & $\%$ & n & $\%$ & n & $\%$ & n & $\%$ & n & $\%$ & n & $\%$ & \\
\hline Collar & 16 & 11.4 & 20 & 12.7 & 16 & 11.1 & 19 & 14.5 & 16 & 10.7 & 20 & 15 & 12 & 9.2 & 0.819 \\
\hline Halo & 86 & 61.4 & 66 & 42.0 & 56 & 38.9 & 61 & 46.6 & 56 & 37.3 & 50 & 37.6 & 46 & 35.4 & 0.023 \\
\hline Surgery & 38 & 27.1 & 71 & 45.2 & 72 & 50.0 & 51 & 38.9 & 78 & 52.0 & 63 & 47.4 & 72 & 55.4 & 0.006 \\
\hline Total & 140 & & 157 & & 144 & & 131 & & 150 & & 133 & & 130 & & \\
\hline
\end{tabular}

Table 3. Intervention for $\mathrm{C} 1$ fracture by age group $(\mathrm{N}=985)$.

\begin{tabular}{|c|c|c|c|c|c|c|c|c|c|c|c|}
\hline & \multicolumn{2}{|c|}{$18-49$} & \multicolumn{2}{|c|}{$50-64$} & \multicolumn{2}{|c|}{$65-74$} & \multicolumn{2}{|c|}{$75-84$} & \multicolumn{2}{|c|}{$85+$} & \multirow[t]{2}{*}{ P value } \\
\hline & n & $\%$ & $\mathrm{n}$ & $\%$ & n & $\%$ & n & $\%$ & n & $\%$ & \\
\hline Collar & 36 & 7.3 & 21 & 9.8 & 16 & 15.8 & 19 & 16.5 & 27 & 41.5 & $<0.001$ \\
\hline Halo & 222 & 45.3 & 106 & 49.5 & 41 & 40.6 & 37 & 32.2 & 15 & 23.1 & 0.009 \\
\hline Surgery & 232 & 47.3 & 87 & 40.7 & 44 & 43.6 & 59 & 51.3 & 23 & 35.4 & 0.410 \\
\hline Total & 490 & & 214 & & 101 & & 115 & & 65 & & \\
\hline
\end{tabular}


odds of receiving a collar in older patients (OR 1.04, 95\% CI: 1.02-1.05, $\mathrm{P}<0.001$ ) (Table 5).

\section{Intervention by hospital region}

The rate of surgical intervention was similar across all four regions $(\mathrm{P}=0.127)$. However, the rates of halo and collar use varied among the four regions (Table 6). Halo use was highest in the West (51.4\%) and this differed significantly from use in the Northeast $(33.5 \%)$ and Midwest $(37.3 \%)(\mathrm{P}=0.025)$. Specifically, the odds of receiving halo intervention in the West were $100 \%$ higher than the odds of patients in the Northeast (OR 2.00, 95\% CI: 1.31-3.06, $\mathrm{P}=0.001)$ (Table 4). In contrast, a greater proportion of patients in the Northeast $(24.2 \%)$ were treated by collar compared to all other regions $(\mathrm{P}<.001)$. The lowest proportion of patients treated by collar was in the South $(7.5 \%)$, followed by the West $(11.3 \%)$ and Midwest $(11.5 \%)$. The odds of receiving a collar for patients in the Northeast were $260 \%$ higher than for patients in the South (95\% CI: 2.07-6.25, $\mathrm{P}<0.001$ ) (Table 5).

\section{Discussion}

Although upper cervical spine fractures are increasing over time, ${ }^{1-3}$ there is no current treatment algorithm for these injuries. As such, optimal management of these fractures remains controversial. A recent study by the senior author evaluated trends in treatment of $\mathrm{C} 2$ fractures. ${ }^{17}$ However, to our knowledge, trends in treatment of $\mathrm{C} 1$ fractures have not been reported in the literature. This study sought to observe differences in treatment of $\mathrm{C} 1$ fractures over time, by age, and across geographic regions using a national data base. Understanding treatment trends of $\mathrm{C} 1$ fractures may help guide future recommendations for the optimal management of these injuries.

In this study of 985 patients admitted from the $\mathrm{ED}$ with $\mathrm{C} 1$ fractures, we observed significant differences in treatment over time, by age, and across geographic regions. Between 2006-2012, the rate of surgical treatment for $\mathrm{C} 1$ fractures increased approximately $30 \%$. Surgical treatment of $\mathrm{C} 1$ fractures generally involves $\mathrm{C} 1-\mathrm{C} 2$ stabilization, ${ }^{4-6,9-12}$ but occasionally requires occipital-cervical fusion. ${ }^{18}$ Despite being associated with increased complications and mortality compared to conservative measures, ${ }^{3}$ surgical treatment of $\mathrm{C} 1$ fractures was not only found to be increasing significantly over time but was also the most common treatment in all years evaluated except 2006 and 2009. There are sever-

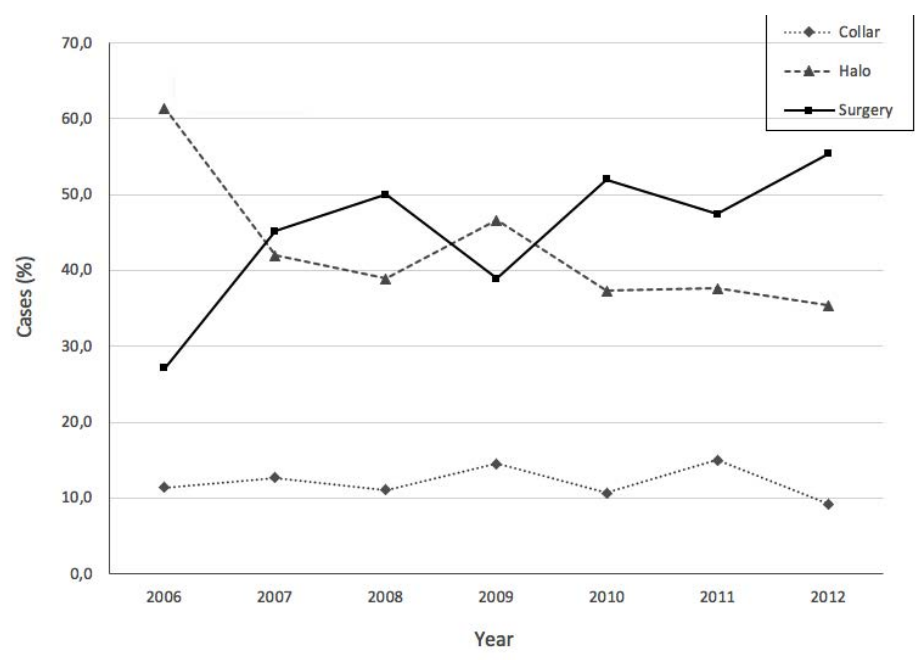

Figure 2. Percentage of C1 fractures stratified by intervention from 2006-2012.

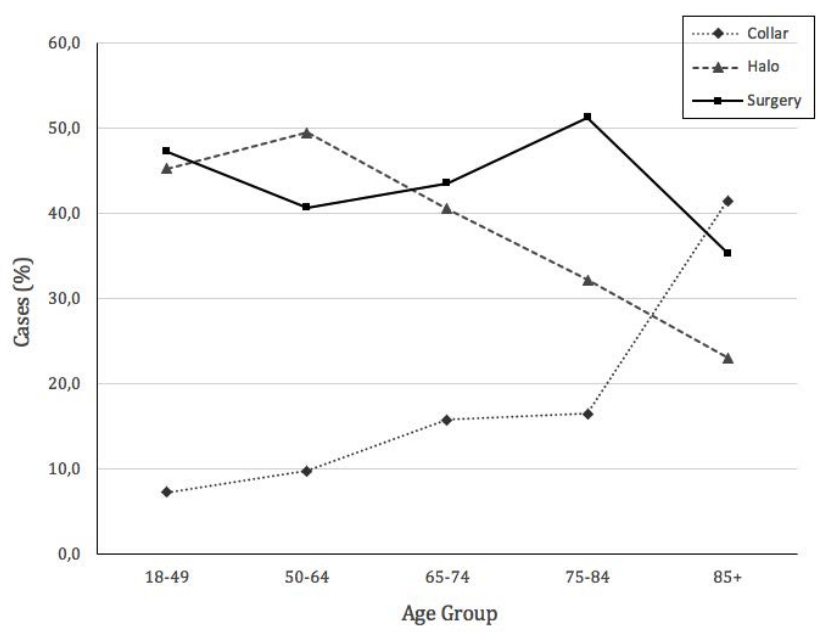

Figure 3. Intervention for $\mathrm{Cl}$ fractures by age group.

Table 4. Multivariable logistic regression for halo use in $\mathrm{C} 1$ fracture.

\begin{tabular}{lccc} 
Predictors & Odds Ratio & $95 \%$ CI & P value \\
Age & 0.99 & $0.98-0.99$ & 0.030 \\
Gender* & 0.86 & $0.66-1.13$ & 0.275 \\
\hline $\begin{array}{l}\text { Hospital region** } \\
\quad \text { Midwest }\end{array} \quad$ & & \\
$\quad$ South & 1.13 & $0.74-1.72$ & 0.563 \\
$\quad$ West & 1.56 & $1.06-2.31$ & 0.026 \\
Chronic conditions & 2.00 & $1.31-3.06$ & 0.001 \\
\hline
\end{tabular}

*Reference: male; **Reference=Northeast.

Table 5. Multivariable logistic regression for collar use in C1 fracture.

\begin{tabular}{lccc} 
Predictors & Odds Ratio & $95 \% \mathrm{CI}$ & P value \\
Age & 1.04 & $1.02-1.05$ & $<0.001$ \\
Gender* & 1.55 & $1.04-2.33$ & 0.034 \\
\hline $\begin{array}{l}\text { Hospital region** } \\
\quad \text { Northeast }\end{array} \quad$ & & \\
$\quad$ Midwest & 3.60 & $2.07-6.25$ & $<0.001$ \\
$\quad$ West & 1.62 & $0.92-2.87$ & 0.095 \\
Chronic conditions & 1.57 & $0.87-2.81$ & 0.132 \\
\hline
\end{tabular}

*Reference=male; **Reference=South. 
Table 6. Intervention for $\mathrm{C} 1$ fracture by hospital region $(\mathrm{N}=985)$.

\begin{tabular}{lcccccccccc} 
& \multicolumn{2}{c}{ Northeast } & \multicolumn{2}{c}{ Nidwest } & \multicolumn{2}{c}{ South } & \multicolumn{3}{c}{ West } \\
& n & $\%$ & n & $\%$ & n & $\%$ & n & \% & \\
Collar & 39 & 24.2 & 28 & 11.5 & 27 & 7.5 & 25 & 11.3 & $<0.001$ \\
Halo & 54 & 33.5 & 91 & 37.3 & 162 & 45.3 & 114 & 51.4 & 0.025 \\
\hline Surgery & 68 & 42.2 & 125 & 51.2 & 169 & 47.2 & 83 & 37.4 & 0.127 \\
Total & 161 & & 244 & & 358 & & 222 & \\
\hline
\end{tabular}

al reasons that may explain our findings. First, surgical stabilization of these fractures allows for early mobilization and is associated with higher union rates compared to non-operative treatment. Also, surgery avoids the additional morbidity of pressure ulcers seen with collar use and increased falls seen with halos. ${ }^{3,5}$ Furthermore, we believe advancements in surgical techniques, instrumentation, and surgical training in cervical fixation makes surgery a more appealing option.

Halo use decreased by approximately $25 \%$ from 2006-2012. This may be attributed to literature during this time period that suggested that halo use in the elderly was associated with increased morbidity and mortality. ${ }^{19,20}$ Meanwhile, collar use stayed consistent over the study period and was the least utilized of the treatments evaluated.

In the elderly, conservative management with a rigid cervical collar may lead to decreased morbidity when compared to halo use or surgery ${ }^{3,19,20}$ despite greater risk of nonunion. ${ }^{3}$ We found that as patients increase in age, the rate of collar utilization increased significantly and was the most common treatment in patients over 85 years old. In contrast, halo use decreased significantly with increased patient age. Jubert et $a l .{ }^{21}$ performed a systemic review of the complications of cervical spine trauma in the elderly. They found that the majority of patients received surgical management for upper cervical spine fractures with decreased mortality when compared to nonoperative care. Delcourt et al. ${ }^{3}$ also reviewed the treatment and complications of upper cervical spine fractures but found higher complication rates and mortality when compared to non-operative measures. These discrepancies are likely related to the lack of studies that include large numbers of patients. Despite analyzing a national database, we were only able to fully evaluate 281 patients over the age of 65 and only 65 patients over the age of 85 . Nevertheless, our findings more closely align with Delcourt et al. ${ }^{3}$ We believe that conservative treatments were more commonly chosen in the elderly population because the morbidity of surgery in this patient population is greater and less well tolerated.

While regional difference in treatment of various spine pathologies have been reported, ${ }^{26}$ this is the first study to assess variations in treatment of $\mathrm{C} 1$ fractures by region. There were no significant differences in surgical rates per region, though the greatest trend towards surgery was in the Midwest. Interestingly, there was a trend towards halo orthosis use over surgery in the West, however, this was not significant. Halo use was highest in the West and lowest in the Northeast and collar use was highest in the Northeast and lowest in the South. In fact, we found that patients in the Northeast had a $260 \%$ greater chance of being treated with a collar than in the South (Table 5). However, it is important to note that collar use was still the least used treatment modality evaluated, regardless of region. Additionally, we found that the odds of treatment in a halo vest was $100 \%$ higher in the West and 56\% higher in the South compared to the Northeast (Table 4). It is possible that these regional variations in treatment are secondary to variations in age within each geographic region. However, the U.S. Census Age and Sex Composition $2010,{ }^{27}$ which illustrates population data by age group in the regions examined in our study (Northeast, South, Midwest, and West), reveals very little variation in the proportion of people per age group by region. Since each age group appears to be represented equally in the four regions studied, it is likely that the variations in treatment by region are independent of age. We believe these regional variations reflect geographic biases in training as well as the lack of consensus in treatment for $\mathrm{C} 1$ fractures. Unlike the subaxial ${ }^{28}$ and thoracolumbar spine, ${ }^{29}$ there are few ${ }^{9}$ validated scoring systems that clinicians can use as a guide for treatment of $\mathrm{C} 1$ fractures. Joaquim et $a l .{ }^{30}$ prospectively validated their previously described algorithm for treatment of upper cervical spine fractures ${ }^{9}$ but the study only evaluated 38 patients.

One of the strengths of this study is that it is the first study to examine geographic variations in treatment of $\mathrm{C} 1$ fractures. Additionally, this study used a large nation- wide database to obtain patient data that could not otherwise have been obtained at the institutional level, especially since $\mathrm{C} 1$ fractures are relatively rare compared to other spine fractures. However, there were several limitations in the present study. Patient data was compiled using the ICD-9 code for $\mathrm{C} 1$ fractures. This code does not differentiate between morphologically different $\mathrm{C} 1$ fracture types (i.e isolated anterior or posterior arch fracture vs. Jefferson fracture $v s$. lateral mass fracture, ect). However, it is unclear that differentiating morphology of these fractures would alter our results since there is no literature to support a treatment algorithm based on $\mathrm{C} 1$ fracture morphology. Additionally, patient reported outcomes were not available in this study. However, this study evaluated the trends in management of $\mathrm{C} 1$ fractures rather than the efficacy of management making patient reported outcomes less applicable.

\section{Conclusions}

This study evaluated the variations in treatment of $\mathrm{C} 1$ fractures over time, by age and by region. The investigation demonstrated that surgical management of $\mathrm{C} 1$ fractures is increasing in frequency over time. Halo use has decreased over time while the frequency of collar use has remained the same over time. Halo was employed much less frequently in the elderly population, whereas collar use significantly increased with age. Furthermore, the treatment of these fractures varies by region - the Northeast had the highest incidence of collar use and the lowest rate of halo use. It is our hope that understanding the treatment trends of $\mathrm{C} 1$ fractures will lead to future recommendations regarding optimal management of these injuries.

\section{References}

1. Matthiessen $\mathrm{C}$, Robinson Y.
Epidemiology of atlas fractures-a 
national registry-based cohort study of 1,537 cases. Spine J 2015;15:2332-7.

2. Baaj AA, Uribe JS, Nichols TA, et al. Health care burden of cervical spine fractures in the United States: analysis of a nationwide database over a 10-year period. J Neurosurg 2010;13:61-6.

3. Delcourt T, Begue T, Saintyves G, et al. Management of upper cervical spine fractures in elderly patients: current trends and outcomes. Injury 2015;46:S24-7.

4. Kakarla UK, Chang SW, Theodore N, et al. Atlas fractures. Neurosurgery 2010;66:60-7.

5. Mead LB, 2nd, Millhouse PW, Krystal J, et al. C1 fractures: a review of diagnoses, management options, and outcomes. Curr Rev Musculoskel Med 2016;9:255-62.

6. Ryken TC, Aarabi B, Dhall SS, et al. Management of isolated fractures of the atlas in adults. Neurosurgery 2013;72:127-31.

7. Fredo HL, Rizvi SA, Lied B, et al. The epidemiology of traumatic cervical spine fractures: a prospective population study from Norway. Scand J Trauma Resusc Emerg Med 2012;20: 85.

8. Platzer P, Hauswirth N, Jaindl M, et al. Delayed or missed diagnosis of cervical spine injuries. J Trauma 2006;61:150-5.

9. Joaquim AF, Ghizoni E, Tedeschi H, et al. Upper cervical injuries - a rational approach to guide surgical management. J Spinal Cord Med 2014;37:13951.

10. Bransford RJ, Alton TB, Patel AR, et al. Upper cervical spine trauma. J Am Acad Orthop Surg 2014;22:718-29.

11. Kamal Y, Ortho MS, Khan HA, et al. Atlas and axis injuries role of Halovest.
Int J Health Sci 2014;8:335-45.

12. Levine AM, Edwards CC. Fractures of the atlas. J Bone Joint Surg Am 1991;73:680-91.

13. Kim HS, Cloney MB, Koski TR, et al. Management of Isolated Atlas Fractures: A Retrospective Study of 65 Patients. World Neurosurg 2018;111:e316-e22

14. Abraham A, Ikramuddin S, Jahansouz $C$, et al. Trends in Bariatric Surgery: Procedure Selection, Revisional Surgeries, and Readmissions. Obesity Surg 2015.

15. Fanuele J, Koval KJ, Lurie J, et al. Distal radial fracture treatment: what you get may depend on your age and address. J Bone Joint Surg Am 2009;91:1313-9.

16. Yoshihara H, Yoneoka D. National trends in the surgical treatment for lumbar degenerative disc disease: United States, 2000 to 2009. Spine J 2015;15:265-71.

17. Grabel ZJ, Armaghani SJ, Vu C, et al. Variations in Treatment of C2 Fractures by Time, Age, and Geographic Region in the United States: An Analysis of 4818 Patients. World Neurosurg 2018. [Epub]

18. Garrett M, Consiglieri G, Kakarla UK, et al. Occipitoatlantal dislocation. Neurosurgery 2010;66:48-55.

19. Horn EM, Theodore N, Feiz-Erfan I, et al. Complications of halo fixation in the elderly. J Neurosurg 2006;5:46-9.

20. Shin JJ, Kim SJ, Kim TH, et al. Optimal use of the halo-vest orthosis for upper cervical spine injuries. Yonsei Med J 2010;51:648-52.

21. Jubert P, Lonjon G, Garreau de Loubresse $\mathrm{C}$, et al. Complications of upper cervical spine trauma in elderly subjects. A systematic review of the literature. Orthop Traumatol Surg Res 2013;99:S301-12.

22. Deyo RA, Gray DT, Kreuter W, et al. United States trends in lumbar fusion surgery for degenerative conditions. Spine 2005;30:1441-7.

23. Harris IA, Dao AT. Trends of spinal fusion surgery in Australia: 1997 to 2006. ANZ J Surg 2009;79:783-8.

24. Loeser JD, Van Konkelenberg R, Volinn E, et al. Small area analysis of lumbar spine surgery in South Australia. ANZ J Surg 1993;63:14-9.

25. Volinn E, Mayer J, Diehr P, et al. Small area analysis of surgery for low-back pain. Spine 1992;17:575-81.

26. Weinstein JN, Lurie JD, Olson PR, et al. United States' trends and regional variations in lumbar spine surgery: 19922003. Spine 2006;31:2707-14.

27. Census Beureau. Age and Sex Composition: 2010. Available from:

https://www.census.gov/prod/cen2010/brief s/c2010br-03.pdf. Accessed 2/9/18.

28. Vaccaro AR, Hulbert RJ, Patel AA, et al. The subaxial cervical spine injury classification system: a novel approach to recognize the importance of morphology, neurology, and integrity of the disco-ligamentous complex. Spine 2007;32:2365-74.

29. Vaccaro AR, Lehman RA, Jr., Hurlbert RJ, et al. A new classification of thoracolumbar injuries: the importance of injury morphology, the integrity of the posterior ligamentous complex, and neurologic status. Spine 2005;30:232533.

30. Joaquim AF, Ghizoni E, Tedeschi H, et al. Upper cervical injuries: Clinical results using a new treatment algorithm. J Craniovert Junct Spine 2015;6:16-20. 